\title{
O ENSINO DE PORTUGUÊS NO BRASIL: AS DESIGUALDADES DA DISTRIBUIÇÃO LINGUÍSTICA
}

\author{
EMERSON DE PIETRI 1* \\ ORCID: https://orcid.org/0000-0001-5060-9891
}

RESUMO: As propostas de renovação das bases teórico-metodológicas do ensino de língua portuguesa se constituíram, a partir da segunda metade do século XX, em resposta à diversidade linguística resultante da chegada, aos bancos escolares, de grupos sociais que historicamente não haviam tido acesso à escolarização formal. Desde então, o processo de urbanização do país se consolidou e a distribuição do ensino fundamental chega à quase totalidade dos alunos em idade escolar, reproduzindo-se, no entanto, as desigualdades no processo de distribuição dos usos socialmente legitimados da língua portuguesa. No atual contexto, os conflitos linguísticos na escola parecem não mais se sustentar em variáveis associadas às diferenças entre o rural e o urbano, ou em contraposições entre cultura oral e cultura letrada, mas nas resultantes históricas de um processo de clivagem linguística que constituiu a distribuição do português no território brasileiro. Observandose as rupturas, dispersões, retrocessos e desigualdades que se reproduzem historicamente no país, neste trabalho questionam-se, com base em proposições mais recentemente elaboradas sobre a distribuição dos bens linguísticos no Brasil, concepções de ensino de língua portuguesa de caráter linear ou progressivo que se desenvolveria no interior de uma unidade linguística entre as variedades linguísticas que a compõem.

Palavras-chave: Ensino de Português; Distribuição linguística; Desigualdade.

\section{TEACHING PORTUGUESE IN BRAZIL: LINGUISTIC DISTRIBUTION INEQUALITIES}

ABSTRACT: Proposals for the renewal of the theoretical and methodological bases of Portuguese language teaching, in Brazil, took place in the second half of the twentieth century, in response to the linguistic diversity resulting from the arrival to school of social groups that historically did not have access to formal schooling. Since then, the country's urbanization process has been consolidated, and the distribution of elementary education reaches almost

\footnotetext{
${ }^{1}$ Universidade de São Paulo, Faculdade de Educação, São Paulo, SP, Brasil.

"Doutor em Linguística Aplicada ao Ensino/Aprendizagem de Língua Materna pela Universidade Estadual de Campinas. Professor de Metodologia do Ensino de Português na Faculdade de Educação da Universidade de São Paulo. Grupo de Pesquisa em Ensino de Línguas e Formação de Professores. E-mail:<pietri@usp.br >.
} 
all students in the school age. In the present context, linguistic conflicts in school are no longer supported by variables associated with the differences between rural and urban, or in a dichotomic opposition of oral culture to literate culture. In this work, based on the most recent studies about the linguistic distribution in Brazil, conceptions of Portuguese language teaching are revisited, observing the ruptures, dispersions, setbacks and inequalities that have been reproduced historically in this country.

Keywords: Portuguese teaching; Linguistic distribution; Inequality.

\section{INTRODUCุÃO}

Neste trabalho, observam-se criticamente proposições pedagógicas para o ensino de língua portuguesa, produzidas e publicadas como propostas acadêmicas ou como documentos oficiais de referência curricular, no Brasil, em resposta às condições de escolarização constituídas com a ampliação do acesso à educação formal a partir da segunda metade do século XX.

Discutem-se as premissas que se encontram na produção dos discursos acadêmicos e oficiais sobre ensino de português na escola, com o objetivo de conhecer seus limites atuais, em face da prevalência dos processos de urbanização, da produção de uma norma urbana popular, e da diversidade crescente de eventos de letramento e sua distribuição.

Pesquisas recentes no campo da sociolinguística têm revisitado proposições a respeito das características da língua portuguesa no Brasil, informando-se das condições históricas que levaram a uma distribuição desigual dos recursos linguísticos no país. Referenciandose nos apontamentos que têm sido feitos nesses estudos sobre as relações entre os processos linguísticos e a formação histórica da dominação política, da exploração econômica e da exclusão social, é possível reconhecer, com base em perspectivas mais recentemente estabelecidas, os conflitos linguísticos que se materializam socialmente e se evidenciam principalmente na escola.

Assim, neste trabalho, as proposições sobre o ensino de língua portuguesa no país são consideradas tendo-se como referência a realidade de clivagem linguística que o caracteriza (LUCCHESI, 2015), e a tensão que se estabelece entre as diferenças linguísticas e os processos de gramatização (AUROUX, 2002; MIGNOLO, 2006), de que resulta a interdição, à maior parte da população, do acesso aos bens econômicos e culturais socialmente valorizados, e à voz nas decisões políticas.

Num contexto em que a variação linguística não mais se fundamenta, para a quase totalidade da sociedade brasileira, nas diferenças entre o rural e o urbano, como nas décadas de 1960 e 
1970, mas na heterogeneidade de um país em que prevaleceu um acelerado processo de urbanização, com sua formação caracterizada pela extrema desigualdade econômica e pela injustiça social, torna-se importante questionar concepções de linguagem e de ensino baseadas em ideias de continuidade, unidade, progressão e nivelamento, considerando-se as rupturas, dispersões, retrocessos e desigualdades que se reproduzem historicamente no Brasil.

Retomam-se, criticamente, as discussões de Pagotto (2007), em que busca observar os efeitos que fatores sociais e interlinguísticos produziram para a constituição do português brasileiro, e as proposições de Lucchesi (2015) sobre os efeitos que os processos de escolarização podem produzir sobre a distribuição do português brasileiro e do português popular brasileiro.

O primeiro aponta para a existência de pelo menos dois portugueses brasileiros que se constituíram e se distribuíram mais ampla e perenemente no país, "um, fruto do contato do português com línguas indígenas e africanas; outro, falado pela elite branca, nos grandes centros urbanos, que evolui a partir do português europeu e pelo contato relativamente frequente com um português renovado que vem da metrópole" (PAGOTTO, 2007, p. 474). Com base em tal perspectiva, o autor retoma as discussões de Tarallo $(1993)^{1}$ quando discute a hipótese de estar em curso um processo de descrioulização do português brasileiro em direção de aproximação para com o português europeu. Pagotto (2007) sugere então outra hipótese:

\footnotetext{
"que vivemos sim, um processo de descrioulização, que no seu início deve ter formado um contínuo dialetal um pouco mais marcado, que numa ponta teria o português pidginizado e na outra o português urbano culto. Segundo essa hipótese, a descrioulização se daria, não em direção ao português europeu moderno, mas em direção a este outro português brasileiro, anulando traços mais extremados de ruptura gramatical." (PAGOTTO, 2007, p. 474)
}

Essas considerações se aproximam das observações de Lucchesi (2015) sobre a clivagem constitutiva da realidade linguística brasileira, em que dois portugueses concorreriam socialmente (os já mencionados português brasileiro e português popular brasileiro). A polarização linguística característica da formação do país (com suas bases estabelecidas na desigualdade econômica constitutiva da sociedade brasileira) passaria por um processo de graduação quando a ampla oferta de escolarização formal e a expansão de agrupamentos sociais urbanos promovem a distribuição de traços do português brasileiro a parcelas da população falantes do português popular brasileiro. Assim, a distribuição social dos letramentos produziria a relativização gradual de uma realidade anterior fortemente polarizada. 
No presente trabalho, retomam-se criticamente as proposições fundamentadas na ideia da construção de um continuum no processo histórico de distribuição linguística no país. Considera-se, aqui, a interdição social e econômica, para amplas parcelas da população, a letramentos socialmente legitimados e economicamente valorizados, interdição operacionalizada com base em princípios de mercantilização dos bens linguísticos em que se fundamentam as clivagens sociais. Questionamse, portanto, quais efeitos produzem para a distribuição linguística o acesso mercantilizado aos bens linguísticos e aos letramentos valorizados, considerados os mecanismos historicamente constituídos para a reprodução das desigualdades linguísticas, sociais e econômicas no Brasil.

\section{AS (NOVAS) PROPOSTAS PARA O ENSINO DE PORTUGUÊS NO BRASIL}

As propostas acadêmico-pedagógicas de renovação do ensino de língua portuguesa que se produziram a partir de meados da década de 70 do século XX, em resposta a mudanças nos modos de distribuição da escolarização no país, responderam, principalmente, às necessidades de construir uma escola que não funcionasse discriminatoriamente em relação aos alunos que começavam então a frequentar os bancos escolares.

O processo de urbanização e industrialização, que se intensificou a partir da década de 1950, se acelerou durante o regime militar instaurado com o golpe de 1964, que reordenou o Estado em função de políticas de desenvolvimento econômico. De caráter eminentemente rural até as décadas iniciais do século XX, o país se torna gradativamente urbano, observando-se o ponto de virada na distribuição populacional nas décadas de 1960 e 1970.

Parcelas da população que até então eram excluídas dos processos de escolarização chegaram à escola e, como demonstraram inúmeros trabalhos na área da sociologia e dos estudos da linguagem, vivenciaram o conflito com a cultura escolar e com a língua nela ensinada. A escola é então considerada, nas proposições acadêmicas, a principal agência de transformação social, num país em luta por sua democratização política (SOARES, 1986; BEISIEGEL, 2013; FREITAS, 2014).

O desenvolvimento das pesquisas em nível de Pós-Graduação, no país, a inserção da Linguística nos cursos de Letras (KATO, 1983) e as preocupações de linguistas em garantir que os estudos da linguagem cuidassem de problemas sociais (CASTILHO, 1988a; 1988b) produziram temas, conceitos, estratégias e objetos de discurso que tinham como objetivo a transformação do ensino de língua 
portuguesa na escola básica (PIETRI, 2003) em busca de uma ação escolar que contribuísse para a produção de uma sociedade mais justa.

Nesse sentido, os saberes produzidos pelos estudos em sociolinguística e as proposições pedagógicas de caráter sociológico ou sociointeracionista fundamentaram, ao longo da década de 1980, até meados dos anos 1990, a elaboração de propostas para o ensino de língua portuguesa (SOARES, 1984; GERALDI, 1984; GERALDI, SILVA \& FIAD, 1996; APARÍCIO, 1999; MARINHO, 2001), cujo objetivo seria o de democratizar o acesso aos conhecimentos linguísticos, concebidos então como instrumentos de ação social e política.

Em meados da década de 1990, entretanto, o país se alinha a reformas econômicas de orientação neoliberal (CHAUí, 2013). As propostas oficiais para o ensino de língua portuguesa elaboradas nesse momento (BRASIL, 1997; 1998; GUEDES, 2002; GERALDI \& GERALDI, 2012) enfatizaram o individualismo, a adequação ao contexto, o desenvolvimento das competências e habilidades, e a competição no mercado de trabalho. ${ }^{2}$ Os efeitos da implantação das políticas neoliberais no país (SADER, 2013) alteraram assim os modos como era projetada a escola, não mais orientada para o desenvolvimentismo econômico de base industrial e a formação de mão de obra qualificada ou especializada, mas para o mercado financeiro e a preparação de indivíduos competentes, dóceis e hábeis, capazes de se adequar às injunções econômicas.

As propostas de ensino de língua portuguesa produzidas para a defesa de uma educação linguística de respeito às diferenças e combate às desigualdades sociais, como as Propostas Curriculares estaduais produzidas em estados diversos da federação (cf. o já referido artigo de GERALDI, SILVA \& FIAD, 1996), são, a partir desse momento, substituídas por propostas curriculares em âmbito federal (BRASIL, 1997) em que prevalece a presunção da unidade linguística no Brasil. Ainda que essas propostas se apresentem como sendo "uma espécie de síntese" do que se produziu de conhecimentos sobre o ensino de português na década anterior (BRASIL, 1997, p. 19), as discussões sobre as diferenças linguísticas e os preconceitos e exclusões que dela se produzem deixam de ser tematizadas. Além disso, as referências a perspectivas sociointeracionistas ou ao interacionismo sociodiscursivo (BRONCKART, 1985; BRASIL, 1997), ainda que mantidas, se encontram submetidas ao discurso das competências e habilidades.

Acentua-se, a partir de meados da década de 1990, a concorrência entre os sistemas de ensino público e particular, invertendo-se a lógica da qualidade com o processo de ampliação da oferta de escolarização pública: a insuficiência do repasse de recursos ao sistema público de 
ensino, e a mercantilização dos processos educacionais nas redes privadas, ampliaram as distâncias entre serviços privados e públicos de educação, concentrando cada vez mais fortemente a posse dos bens simbólicos social e economicamente valorizados sob o domínio das elites econômicas. Ofertada a educação como uma mercadoria, os sistemas educacionais respondem à divisão implementada entre o serviço privado e o serviço público (cf. FREITAS, 2004; OLIVEIRA, 2009; PERONI \& CAETANO, 2015), de modo que as classes sociais que possuem capacidade para investir em sua compra adquirem recursos de língua portuguesa valorizados socialmente, restando às classes sociais historicamente exploradas a interdição a usos e formas da língua que são continuamente revalorados em sua circulação nesse mercado.

Nesse sentido, ações de reconfiguração curricular; de atualização de conteúdos e sua apropriação para a composição de materiais didáticos; de estabelecimento de saberes a serem examinados em avaliações de larga escala em redes de ensino e em sistemas educacionais (BOURDIEU, 1996; AFONSO, 1999), impactam desigualmente os serviços públicos e privados de educação: podem representar a indicação de defasagem, devido às escolas e professores não terem condições de se apropriar prontamente dessas mudanças e implementá-las em seu contexto de ensino; ou podem representar inovação, avanço, compondo um novo produto a ser ofertado no mercado. Apresentam-se assim, regularmente, ao mercado, novas linhas de produtos a serem consumidos por determinadas parcelas da população e não por outras.

Além disso, as descontinuidades dos processos produtivos, as rupturas institucionais, bem como a violência, suplência ou ausência do Estado para parcelas da população (FELTRAN, 2014) são, dentre outros, fatores que historicamente reproduzem a desigual produção, valoração e distribuição dos recursos linguísticos no país.

\section{A PRODUC̣ÃO HISTÓRICA DA CLIVAGEM LINGUÍSTICA}

Uma das características que sobressaem em relação à distribuição do português no território brasileiro é sua prevalência em relação a outras línguas nele coexistentes. Historicamente, essa posição se estabeleceu em função de processos de distribuição linguística realizados principalmente pela necessidade de subsistência no novo território (como no caso da distribuição do português brasileiro adquirido pelos africanos escravizados), ${ }^{3}$ ou por força de lei (como no caso da obrigatoriedade do uso do português nas colônias portuguesas, em determinação de 1757 sob a voz do Marquês de Pombal). 
A ampliação do uso da língua portuguesa no território se fez em processos paulatinos de substituição das línguas dos povos nativos, principalmente pela eliminação progressiva das línguas indígenas, ou pela dizimação dos povos que as falavam. No caso dos escravizados africanos e descendentes de africanos, trata-se de aprendizado do português como língua estrangeira, sob o jugo do escravizador, em resposta à necessidade de produzir meios de comunicação entre falantes de diferentes línguas trazidas de seus grupos de origem.

Em todos esses casos mencionados, aos quais ainda se podem somar a intensa imigração portuguesa ao Brasil, durante o período colonial — o que produziu as condições para que não se desenvolvesse plenamente um processo de crioulização (LUCCHESI, 2008) —, e as proibições a línguas de imigração, no século XX, o que caracteriza a implantação da língua portuguesa no território brasileiro é, sobretudo, a violência com que se realizou historicamente.

Nesse sentido, quando se trata de variação linguística e dos impactos que essa realidade da variação acarreta para os processos de educação linguística, principalmente os formais, e, destes, os escolarizados, não se pode deixar de considerar que a variação em jogo é, portanto, constitutivamente histórica. Essa historicidade, porém, não refere o tipo de variação que os estudos em sociolinguística observam em suas bases estruturais, funções de processos de deriva linguística (cf.: LUCCHESI, 2012; NARO \& SCHERRE, 1993; 2007; LOBATO, 2006), mas uma historicidade relativa à constituição de diferentes processos de implantação da língua em momentos históricos diversos; em regiões geográficas distintas; em grupos culturais específicos; em classes sociais menos ou mais bem definidas; em processos econômicos e políticos com sentido de permanência ou de descontinuidade, em certos momentos históricos e em determinadas regiões; na coexistência de diferentes gerações em fases distintas de processos sociais, econômicos, culturais e políticos.

Resultante dos processos históricos fundados na desigualdade social, política e econômica, o que se encontra no Brasil não é a existência de um monolinguismo cujas variedades se caracterizem apenas pelo caráter diafásico, diastrático ou diatópico. Os tipos de variação se desenvolvem historicamente, assim, não apenas como uma deriva secular, mas são atravessados pela realidade histórica de uma clivagem linguística: trata-se, como propõe Lucchesi (2001; 2006; 2012; 2015), de uma realidade linguística polarizada, entre variedades de português que se diferenciam em suas bases estruturais, entre uma norma linguística culta, própria à pequena parcela da população escolarizada para a aquisição do português padrão e de uma norma 
culta do português brasileiro (PB); e variedades linguísticas populares, vernáculas (o português popular brasileiro - PPB), resultantes históricas dos processos de aquisição de povos colocados em contato na formação e desenvolvimento da colônia, e, em sequência, do país.

Como aponta Lobato (2006), não se trata apenas de deriva o que teria diferenciado o PB do português europeu (PE), mas, de fato, da formação de outras bases sintáticas e semânticas em que se fundamenta o primeiro, pois aprendido como língua estrangeira por adultos. Nessas condições, características das línguas faladas pelos que aprenderam o português no Brasil-Colônia condicionaram os recursos linguísticos acrescidos às suas bases gramaticais. Como defende esta autora, ao observar características de línguas indígenas que se encontram no $\mathrm{PB}$, a diferença entre este e o PE se evidencia em estruturas sintáticas específicas de um e de outro (como o quadro de pronomes e seus empregos, por exemplo), mas, também, semanticamente, no fato de o PB se caracterizar como uma língua extensional, enquanto o PE se caracterizar pela intensionalidade, isto é: português do Brasil licenciaria "sujeitos por meio da leitura extensional da expressão nominal, pela verificação do seu traço categorial, e o português europeu, por meio da leitura temática da expressão nominal, pela verificação do seu traço temático" (LOBATO, 2006, p. 15). ${ }^{4}$

$\mathrm{Na}$ perspectiva de Lucchesi (2006), trata-se, ainda, entre o $\mathrm{PB}$ e o PPB, de diferenças que polarizam duas realidades linguísticas constituídas historicamente: uma voltada para a identificação com a língua da metrópole, norma identificada com o lugar de status perseguido pelas elites no Brasil-Colônia; outra formada em processos de aquisição de uma língua estrangeira (o português falado no Brasil) aprendida na fase adulta pelos indígenas, mas, principalmente, pelos africanos escravizados em seu grande contingente populacional constituído por diferentes línguas de origem, num processo denominado pelo autor de transmissão linguística irregular (LUCCHESI, 2003). Teria sido produzida, assim, uma realidade linguística clivada no Brasil, polarizada entre as classes privilegiadas e a massa populacional pobre/explorada.

Ainda que se considere o continuum que propõe Lucchesi (2015) para observar as relações entre a norma culta e a norma popular dadas as interinfluências que elas podem exercer uma na outra, numa sociedade em que os usos de linguagem se distribuem amplamente com os meios de comunicação de massa, e, mais recentemente, as plataformas digitais - , as interdições sociais exercem contínua e fortemente sua função discriminatória, de modo a garantir a avaliação 
dos sujeitos pelos seus usos de linguagem e pelo seu capital linguístico (cujo valor é definido com base nas possibilidades de investimento no mercado de bens simbólicos).

É preciso considerar, por exemplo, que, em contextos urbanos periféricos, a língua distribuída pelo Estado não encontre possibilidade de entrada em espaços dominados por uma ordem alternativa ao poder público: como aponta Feltran (2014), nesses espaços, a economia, a religião e o controle da violência se fazem à margem de Instituições oficiais ou tradicionais, estando sob o domínio do comércio informal, das religiões neopentecostais e do crime organizado.

Nesses espaços, a concorrência se estabelece não entre a norma culta ou a norma padrão e variedades advindas do rural ou do rurbano ${ }^{5}$ (BORTONI-RICARDO, 2004a), mas entre normas urbanas distintas: a língua oficial, levada pelo Estado, e as normas populares específicas, próprias aos grupos (econômicos, religiosos, criminosos) que definem as relações sociais num território determinado (cf.: FELTRAN, 2014). Essas normas respondem a valores culturais e a modos de letramento próprios às práticas sociais em que se associam os sujeitos nesses contextos: os documentos escritos de referência (como os textos bíblicos, por exemplo), e as práticas sociais tradicionalmente associadas a rituais específicos, são apropriados segundo regras próprias às práticas discursivas desenvolvidas pelos grupos sociais que se constituem nas regiões urbanas economicamente periféricas.

Outro modo de compreender a situação, portanto, seria considerar que em cada diferente contexto de uso em que prevaleçam o PB ou o PPB se encontrem realidades de variação linguística específicas, isto é, os tipos de variação tradicionalmente apontados pelos estudos em sociolinguística se encontrariam funcionando em ambos os polos indicados, segundo as especificidades de um e de outro português brasileiro (PB e PPB) que constituem esses polos. PB e PPB teriam cada um deles variações diafásicas, diatópicas e diastrásticas próprias, interinfluenciáveis de um a outro português, como será discutido adiante.

Assim, é preciso que as referências sociolinguísticas em que se fundamentam as propostas de língua portuguesa, no país, desde finais da década de 70 do século passado, sejam revisitadas, de modo a considerar que os tipos de variação linguística sejam observados em suas especificidades para cada um dos tipos de português falados no país. Não mais se trataria somente do conflito entre a língua da escola (a norma culta/o português padrão) em face das variedades linguísticas 
próprias a regiões, faixas etárias e monitoramento estilístico. Trata-se de variações linguísticas específicas para um e para outro português (o PB e o PPB). Apenas o respeito à variedade linguística do aluno, ou o enriquecimento dessa variedade com a exposição a práticas de letramento e usos formais da linguagem, não tem se mostrado suficiente - como evidenciam pesquisas acadêmicas ou resultados de avaliações de aprendizagem nos sistemas escolares ${ }^{6}$ - para que parte importante desses alunos vença o obstáculo que separa seu conhecimento e uso do $\mathrm{PPB}$ do conhecimento e uso do $\mathrm{PB}$ e às especificidades de sua modalidade escrita.

Em relação à distribuição da escrita e das práticas de letramento, cada um dos dois tipos de português também apresentaria características próprias, considerados os efeitos que o aprendizado da escrita produz sobre um português associado a uma norma baseada nos usos escritos legitimados historicamente, e os efeitos do aprendizado da escrita nos usos do português caracterizado por sua distância sintática em relação à norma culta do português brasileiro.

Tal clivagem, que é histórica e socialmente definida, ao ser ocultada pelo imaginário de um país monolingue, resulta em propostas de ensino e de aprendizagem de língua na escola pautadas no princípio da suposta igualdade de condições: todos os brasileiros que vão à escola falam português, num ponto de seu continuum, do menos culto para o mais culto $;^{7}$ portanto, todos estariam em condições semelhantes de desenvolvimento dos usos do português legitimado pelas práticas letradas valorizadas historicamente.

A observação da diferença entre um e outro português no Brasil leva, assim, a revisitar as discussões sobre a distribuição de língua pela escola. Não se trata, no caso brasileiro, da diferença de usos linguísticos associada a valores culturais relativos e sua distribuição social no mercado dos bens simbólicos (BOURDIEU, 2007). No caso brasileiro, por não prevalecer um continuum linguístico, mas uma clivagem linguística, entre o português brasileiro e o português popular brasileiro, cada um com suas especificidades estruturais, a dificuldade de apropriação da norma culta na escola, pelas classes pobres, não seria decorrente da impossibilidade de mensuração relativa do valor que tem um dado bem simbólico na cultura dominante, pois, para a população pobre historicamente excluída da produção social, esses valores na maior parte das vezes sequer são conhecidos.

A dificuldade de aprendizagem da norma culta pela população pobre se faz pela necessidade de se apropriar de estruturas sintáticas da língua-alvo que, em lugar de ser ensinada como uma estrutura gramatical diferente, é ensinada como se compartilhasse com a língua do aluno 
falante do português popular brasileiro a mesma estrutura. Assim, a não consideração da diferença garante que o ensino se naturalize como suposto desenvolvimento de uma língua que já se conhece, quando se trata de fato do aprendizado de estruturas que não se possui. ${ }^{8}$

Considerando-se que o aprendizado de uma língua constitui um processo ideológico não apenas no que se refere ao estabelecimento de um valor social associado a uma variedade linguística, mas também à apropriação de categorias de compreensão da realidade (MIGNOLO, 2008), a clivagem linguística que se associa à desigualdade (apartheid) social e econômica no Brasil se faz também pela exposição a uma realidade que não pode ser apreendida devidamente em razão de não estarem disponíveis ao sujeito as categorias que fundamentam a discriminação legitimada dos elementos dessa realidade: para as classes privilegiadas que se estabeleceram no país, com a conformação a categorias de apreensão da realidade que as fazem compreender os dados a partir de valores implantados pelos colonizadores ao longo da história, tratar-seia, num processo de descolonização (que essas classes, ideologicamente, denegam, por não se observarem como subjugadas, mas como dominantes), de "aprender a desaprender", como propõe Mignolo (2008). Isto é, trata-se de constituir outras categorias de apreensão da realidade que confrontem as categorias impostas pelo colonizador em seu objetivo de dominação, de submissão do povo dominado.

No caso das classes exploradas/expropriadas, tratar-se-ia de aprender a desaprender num processo em que as próprias categorias de apreensão da realidade pelas classes privilegiadas são oferecidas de modo precário, dada a distribuição desigual, injusta, dos bens sociais num país como o Brasil.

Constituem-se assim, historicamente, processos de recategorização dos modos de apreensão da realidade que se sustentam em um princípio de desvalorização cultural que percorre o país como um todo: as classes dominantes se observam inferiores às culturas estrangeiras cujos valores desejam e a que se submetem (PAGOTTO, 1999); desse modo, ainda que usuários da norma culta, a representação que têm de sua língua não se aproxima da norma padrão desejada, que a ideologia associa à língua cifrada nas gramáticas tradicionais, fundada num ideal de língua portuguesa, esta também vista como inferior à língua do poder dominante atual, o inglês. Produz-se assim o sentimento de insegurança linguística (cf.: LUCCHESI, 2015), e, portanto, a insegurança quanto às bases referenciais de seus modos de apreensão da realidade (o que acentua o servilismo, a submissão à cultura dos colonizadores, aos referenciais estrangeiros que informam as chaves de leitura do mundo). 
As classes pobres se encontram, portanto, num processo de dupla dominação: em relação à língua, são estratificados com base num processo de desvalorização linguística em relação ao português brasileiro. No que se refere à cultura, são cobrados a se apropriar dos valores da elite, cifrados em escrita padrão e em norma culta, sem que possuam a priori a base gramatical e lexical para essa recepção, nem as referências para a compreensão dos produtos culturais que são simbolizados nessa norma e nesse padrão.

Cumpre-se, de fato, a função que tem tido o Estado no Brasil como instrumento de poder das elites econômicas: esvaziar as possibilidades de atuação política das classes subalternas, o que favorece a permanência da subalternidade dócil. ${ }^{9}$

\section{A INSUFICIÊNCIA DOS PROCESSOS DE GRAMATIZAC̣ÃO NO BRASIL}

O objetivo neste momento é o de observar de que modo o processo de gramatização, no sentido que lhe confere Auroux (2000), produz efeitos sobre a constituição da língua portuguesa, considerada a clivagem linguística e a definição/imposição de categorias de compreensão da realidade, mencionadas na seção anterior.

Segundo Auroux (2000), o processo de gramatização, tal como desenvolvido na modernidade europeia, se realizou entre anos finais do século XV e décadas iniciais do século XVI, e consistiu na produção de gramáticas e de dicionários das línguas estabelecidas para serem línguas nacionais dos Estados-nação europeus que, naquele momento, se consolidavam enquanto tais.

De acordo com o autor, o processo consistiu em descrever as línguas em bases categoriais equivalentes às da gramática latina. Com isso, garantia-se um passado nobre para cada uma das línguas, dada sua suposta similaridade ao latim, e, assim, elas poderiam ocupar o lugar que até então era ocupado pelas línguas clássicas para a produção e circulação de cultura e ciência.

Foi um movimento que produziu, concomitantemente, efeitos internos a cada Estado, na produção de seu território nacional, e externos, da definição das diferenças e limites para com os outros Estados-nação europeus. Internamente, a gramática e o dicionário se faziam instrumentos - tecnologias, na acepção que lhes confere o autor - para a normatização linguística, para a supressão das diferenças em favor de uma língua única, que, controlada em suas formas, podia ser então ensinada para o seu ainda não-falante. Com a distribuição mais ampla da variedade linguística definida para representar a língua de nação, tornava-se possível produzir o imaginário de pertencimento a 
uma unidade nacional, a ideia de que todos os habitantes do território, identificados a uma suposta língua materna, única, compartilhavam as mesmas origens e culturas.

Nas relações externas, a gramatização das línguas e a identificação de cada uma a uma dada nacionalidade teria possibilitado que se produzissem efeitos de diferença, fortalecendo a filiação identitária: um sujeito seria francês por ter como língua materna a língua francesa, mas, também, pelo fato de não ter como língua materna o alemão, ou o espanhol, ou o inglês, etc. Os limites nacionais se estabeleceriam também com base na diferença para com o outro estrangeiro.

Um fato definidor do processo, porém, diz respeito à constituição de uma rede (meta)linguística no território europeu ocidental (rede que talvez esteja na base da própria possibilidade da modernidade): as línguas próprias permitiram a cada um dos Estadosnação produzirem suas culturas e sua ciências nos seus próprios vernáculos, mas permitiram também, pelo fato de as gramáticas terem sido produzidas com as mesmas bases categoriais, que se pudessem traduzir as manifestações de um povo na língua do outro. Isso teria realizado na Europa a formação de uma rede de produção de ciência e tecnologia, o que ajudaria a se compreender o próprio evento do colonialismo: essa região geográfica, a Europa ocidental, desenvolveu a partir de então os instrumentos científicos, tecnológicos, culturais e linguísticos para se impor aos povos de outras partes do globo.

A gramatização sustentaria, portanto, todo o processo de dominação de outros grupos humanos, pelas possibilidades de avanço científico e tecnológico (dentre eles, o militar), mas também pelo fato de gramática e dicionário serem instrumentos de imposição linguística e cultural aos povos dominados. Trata-se, assim, de dominar pela imposição de categorias de compreensão da realidade (MIGNOLO, 2008).

No que se refere ao caso brasileiro, é preciso considerar que a colonização portuguesa, distintamente dos tipos de colonização impostos por outros países europeus, não se fundamentou, inicialmente, na imposição cultural dos lusitanos aos povos habitantes da colônia na América. Os jesuítas, para a conversão dos indígenas, produziram gramáticas de línguas gerais constituídas no território, realizando seu trabalho catequético na língua produzida a partir das línguas dos nativos. Essa não imposição primeira do português como língua da colônia garantiu que o território permanecesse multilingue por um longo período da colonização portuguesa. Mesmo os portugueses aqui habitantes se comunicavam nas línguas gerais, aprendendo a língua portuguesa, seus filhos, na escola (cf.: LUCCHESI, 2008). 
Situação semelhante teria havido com as línguas dos povos africanos trazidos escravizados ao Brasil. Para responder à necessidade de comunicação entre os escravizados, e entre eles e os escravizadores, estabeleceram-se também línguas veiculares, além da aquisição da língua portuguesa de forma irregular (LUCCHESI, 2003), para o contato com os falantes do português: "O aparecimento da língua veicular africana se explica pela economia da
comunicação, pela necessidade de ultrapassar o esfacelamento desses diversos
falares muito próximos tipologicamente da língua africana utilizada nas minas, no
século XVIII, e só publicado em 1945, em Lisboa, é o documento mais importante
e "precioso" sobre as línguas africanas no Brasil, porque testemunha a existência
de uma língua veicular africana designada como Língua Geral, provavelmente
em referência à língua geral indígena (BONVINI; PETTER, 1998, p. 75-76)"."
(PETTER, 2005, p. 203)

O documento em questão, "Lingoa gal de Minna, tradurida ao nosso Igdioma, por Antonio da Costa Peixoto, Curiozo nesta Siencia, e graduado na mesma faculdade: E. o", ou, como aparece no frontispício do manuscrito, "Obra Nova da Lingua Geral de Minna, redigido em Ouro Preto, em 1731/1741", de autoria de Antonio da Costa Peixoto, tinha como objetivo "facilitar aos senhores de escravos o aprendizado da língua utilizada nas minas” (PETTER, 2005, p. 203). De acordo com a autora, esse documento permite observar que:

"O século XIX não nos oferece uma documentação especificamente linguística como a dos séculos precedentes, mas confirma dois fatos: a existência de um plurilinguismo africano, sobretudo em Salvador, e a identificação de uma maneira particular de expressão em português dos negros escravos.” (PETTER, 2005, p. 204)

Tal situação em que o português não se impunha como língua da colônia permaneceu oficialmente, portanto, além do ano de 1757, quando Marquês de Pombal estabeleceu, por força de lei, a obrigatoriedade do uso do português e apenas dele, nas colônias de Portugal.

A distribuição linguística do português oficial, no entanto, não tinha condições de se fazer de forma ampla, sem instituições para garantir essa distribuição, num modo de relação com a colônia que se caracterizou mais pelo retrocesso político, econômico e cultural em que se posicionava Portugal, que por outro tipo de projeção da metrópole em relação à sua posição no mundo colonial.

Nesse sentido, o que se tem parece ser um movimento antimoderno ainda mais forte que aquele que Quijano (2005) aponta para a situação da Espanha em face de seu lugar no processo de colonização, se se considera que Espanha implementou instituições de ensino nos territórios colonizados muito antes de processo nesse sentido ter sido iniciado no Brasil. 


\section{DESIGUALDADE ECONÔMICA E DESIGUALDADE DA DISTRIBUIÇÃO LINGUÍSTICA}

Quijano (2005) observa a direção tomada pela Espanha ao longo do processo de colonização: após os movimentos de descoberta e dominação de novos territórios, resultado do investimento em possibilidades tecnológicas que permitiram as navegações e a subjugação de povos nas regiões dominadas, opera-se um movimento de retorno a fases pré-modernas, em que a dominação se faria não com base na supremacia do esclarecimento cultural e científico, mas com base no domínio pelo uso da força, da violência. Esse movimento, que vale para Espanha, mas, em certa medida, se pode também apontar para Portugal, posiciona esses Estados em situação de dependência econômica em relação a outros Estados europeus, e, fragilizados economicamente, a manutenção de suas colônias passa a ser garantida com o uso da força. Assim, em lugar de avançar nos progressos que se estabeleciam na modernidade de parte da Europa ocidental, Espanha (e Portugal) retrocedem a condições características da Idade Média.

Esse movimento teria acentuado ainda mais um modo de organização social que, segundo o autor, teria se estabelecido, pela primeira vez na História, na América. ${ }^{11}$ Esse modo de organização se fez pautado na ideia de raça, e escalonou socialmente os territórios colonizados numa verticalidade que tinha o europeu branco ocidental na posição mais alta, de dominância; os indígenas, no intermédio, no lugar da servidão; e os negros trazidos da África e, depois, seus descendentes nascidos na colônia, na posição de escravizados.

Observa-se, assim, uma dupla estrutura que define a distribuição social e econômica nas colônias, com os efeitos que permanecem se reproduzindo na atualidade, resultantes desse processo histórico. Trata-se de uma distribuição desigual da gramática da língua nacional, que se oferece de forma plena para uma elite econômica e política, e de forma precária para as populações pobres, numa dispersão horizontal que é cruzada pelo eixo vertical do escalonamento social, político e econômico baseado na ideia de raça (o que, posteriormente, se refletirá na divisão das classes sociais no Brasil).

Essa organização social e seus efeitos podem ser observados nos dados reproduzidos no gráfico abaixo, sobre os índices de analfabetismo entre pessoas com 15 anos ou mais, nas cinco regiões brasileiras, em função da distribuição racial: 


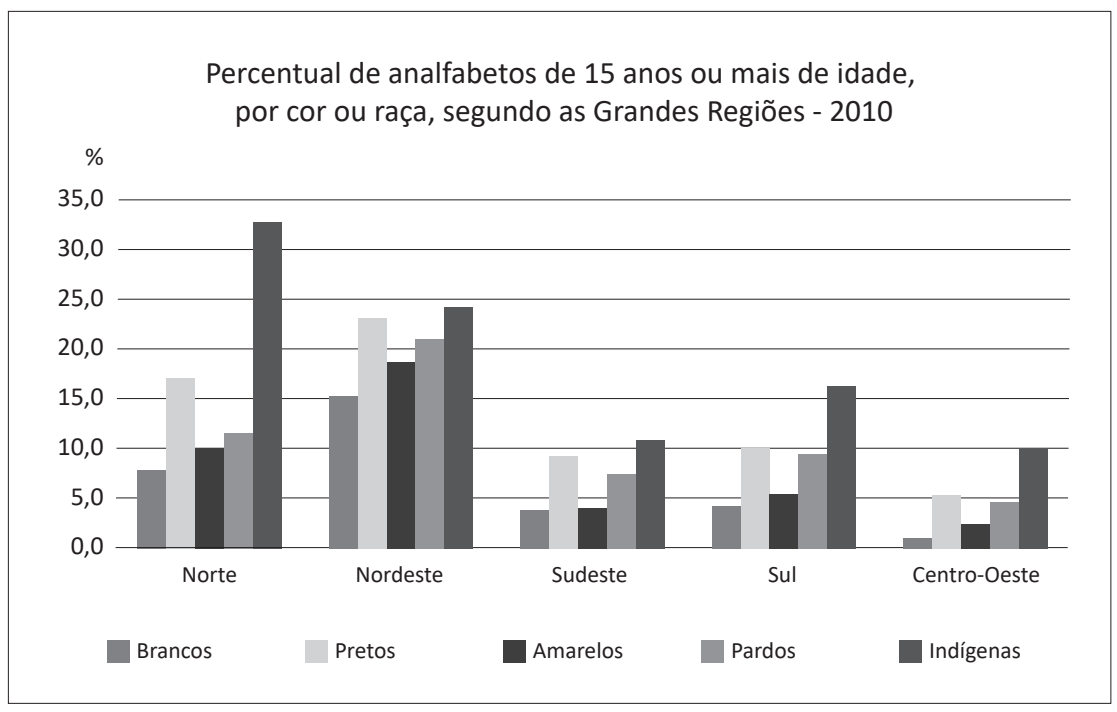

Fonte: (IBGE, 2010, p. 109)

O gráfico com dados de 2010 evidencia a polarização que historicamente se constituiu na distribuição linguística no país (em função de desigualdades econômicas). O grupo populacional com maior quantidade de sujeitos que não se apropriam da modalidade escrita da língua é o grupo dos indígenas, em qualquer das regiões observadas. As causas se observam na posição que os indígenas ocuparam historicamente na formação da sociedade brasileira: escravizados ou no lugar da servidão, foram dizimados em sua extensa maioria; os grupos que permaneceram se encontram, em grande parte, em situações de contato ou integrados às sociedades não indígenas. A princípio não aculturados linguisticamente, foram trazidos à cultura europeia, induzida no território pelos colonizadores, com o uso de línguas gerais. Quando não aculturados desse modo, o português foi aprendido num processo de transmissão linguística irregular (LUCCHESI, 2003), como mencionado, devido à sua aquisição ter sido feita como língua estrangeira aprendida por adultos (LOBATO, 2006).

Trata-se, no caso dos indígenas, de uma população que ainda atualmente se encontra em condições-limite no que se refere à sua integração à sociedade decorrente da colonização europeia ocidental. É a heterogeneidade mesma dos modos de relação das culturas indígenas com as não indígenas que se pode observar em seus efeitos no gráfico de distribuição linguística. Dessa heterogeneidade de relações sociais, culturais e econômicas, dos tipos de escolarização, e dos modos de aquisição do português pelos indígenas (um dos 
fatores de constituição do português popular brasileiro), ${ }^{12}$ resulta a proporcionalidade expressa nos resultados da pesquisa que apontam para a não aquisição da escrita principalmente pelos povos indígenas.

O segundo grupo populacional que apresenta as maiores taxas de analfabetismo é a formada pelos que se autodeclaram pretos, seguidos pelos que se autodeclaram pardos, ou seja: trata-se da população formada pela ascendência africana e pelos processos de miscigenação que se fizeram no encontro dos povos africanos, indígenas e europeus, e os descendentes desses povos, no país. Esse grupo, se somados pretos e pardos, se mostra ainda mais numeroso que o grupo dos indígenas, e é o grupo que, historicamente, se fez responsável, segundo Lucchesi (2008; 2012; 2015), pela distribuição da língua portuguesa no território brasileiro: os escravizados de origem africana, ou já nascidos em território brasileiro, distribuíram a língua portuguesa, em sua aquisição irregular, às diversas regiões do território a que eram levados em função das atividades econômicas que se desenvolviam na colônia (com os ciclos de mineração, os agrícolas e os extrativistas, principalmente).

Os resultados da pesquisa do IBGE evidenciam, assim, os efeitos que produz na atualidade a clivagem linguística que se constituiu historicamente no país. São dados que reforçam o argumento da polarização entre dois tipos de português coexistindo em relações contraditórias de integração e repulsa na sociedade brasileira.

Mas o gráfico permite ainda observar que a base para essa clivagem e polarização é econômica, pois a distribuição linguística e o escalonamento social nas colônias se fizeram, obviamente, por essa matriz. Assim, os dados referentes à região nordeste do país evidenciam que a apropriação da escrita do português apresenta índices muito altos e em proporções muito mais próximas para todas as raças indicadas no censo. Essa realidade pode se apresentar em razão de historicamente essa região ter se mostrado economicamente menos desenvolvida em comparação com as demais regiões brasileiras que se industrializam a partir das décadas iniciais do século XX. Considerada a concentração de renda e de poder político que caracteriza historicamente a formação da região nordeste, e, também, a presença desigual do Estado no atendimento às populações que aí habitam, o que restringiu a oferta de escolarização e sua qualidade, observa-se uma parcela muito mais restrita de falantes que possam se apropriar da norma do português brasileiro, em face de uma massa populacional extensa falante do português popular brasileiro. 
Entre as demais regiões, consideradas diferenças quantitativas relacionadas ao fator econômico, observa-se proporcionalidade entre os grupos raciais e as taxas de analfabetismo (evidenciada na região norte, por certo, maior quantidade relativa aos indígenas).

No que se refere ao grupo caracterizado por "amarelo", com taxas de analfabetismo superiores ao grupo dos "brancos" (excetuada a região sudeste, em que há equivalência entre esses dois grupos), a aquisição do português por adultos imigrantes, e, também, a perseguição a línguas de imigrantes no início do século XX, no Brasil, no período das grandes guerras, talvez possam ser vistos como os condicionantes históricos para que esse grupo apresente restrições na aquisição da escrita padrão do português.

Os dados da pesquisa de distribuição de língua escrita no país evidenciam a atuação do processo de clivagem, de polarização a que está condicionada historicamente essa distribuição no Brasil. Mas também apontam para o diálogo entre um e outro desses polos e para sua interinfluência (LUCCHESI, 2015), uma vez que, nas regiões em que o processo de industrialização se mostra mais desenvolvido - com os desenvolvimentos de comércio, finanças, educação, comunicação, cultura, que tal processo acarreta —, os níveis de analfabetismo são menores (são regiões que possuem, inclusive, densidades demográficas maiores). Assim, o aumento da renda, a oferta de escolarização, e o contato mais constante entre classes sociais, ampliariam as possibilidades de trocas linguísticas, de diálogo entre o PB e o PPB, e, portanto, de circulação dos sujeitos entre um e outro português brasileiro, o que leva a um processo de graduação na realidade polarizada anteriormente constituída, como já mencionado.

A observação da distribuição linguística no Brasil, dessa perspectiva, permite revisitar as discussões sobre o ensino de língua portuguesa na escola pública e considerar outras possibilidades de se definir o problema a partir de como se configura a oferta da escolarização básica no país depois de consolidados os processos de urbanização e industrialização desenvolvidos ao longo do século XX, e implementadas as políticas neoliberais em suas décadas finais.

\section{DISTRIBUIC̣ÃO DESIGUAL DE ESCOLARIZAC̣ÃO E RUPTURAS NOS PROCESSOS DE LETRAMENTO}

As discussões sobre ensino de língua portuguesa no Brasil se intensificaram a partir da segunda metade do século XX, em razão 
da reconfiguração da sociedade e da constituição de condições que anteriormente não existiam: a oferta de escolarização básica pública obrigatória a contingentes amplos da população, no interior do projeto de desenvolvimento econômico estabelecido pela ditadura militar; a reconfiguração do currículo da escola básica para responder a esse projeto de escolarização, na década de 70; o desenvolvimento de uma estrutura institucional de produção científica e tecnológica que possibilitou o desenvolvimento das pesquisas em linguagem e em educação, nas Universidades, majoritariamente em seus programas de Pós-Graduação. Esses três fatores (democratização do acesso à escola básica; configuração curricular; pesquisa em educação e linguagem) se produziram, no Brasil, de modo interconstitutivo, como observado em trabalho anterior (PIETRI, 2010).

A chegada à escola de sujeitos provenientes de grupos sociais historicamente não escolarizados, com variedades linguísticas próprias à cultura oral de proveniência do meio rural, produziu a problemática que passou a ser fundamental para as discussões sobre ensino de língua portuguesa na escola, desde meados do século XX, num processo que se intensificou a partir da década de 70 , como mencionado. O que significava ensinar o português escrito, ou sua norma falada culta, na escola pública, a estudantes não falantes desse português, provenientes de grupos sociais sem histórico de escolarização? Que escola era essa que se formava então (FREITAS, 2014), e como garantir que ela se constituísse numa instituição que levasse à transformação social, com vistas a uma sociedade menos desigual (SOARES, 1986), e não à reiteração dessa desigualdade com a chancela da suposta incapacidade dos que não conseguiram responder às demandas escolares?

Os meios de diminuir os conflitos entre a língua da escola e $\mathrm{a}(\mathrm{s})$ línguas(s) — as variedades linguísticas — dos alunos passam a ser os objetivos fundamentais das discussões que se realizam então sobre o ensino de português, com importantes aportes da sociolinguística, e, no caso dos anos iniciais, do construtivismo de base piagetiana proposto por Emília Ferreiro (cf.: PESIRANI, 2014). Ambas as referências epistemológicas orientaram parte importante das pesquisas e proposições pedagógicas para o ensino de português, com vistas à solução dos problemas de aprendizagem decorrentes das distâncias entre a cultura escolar e a cultura do aluno que à escola então chegava.

A tabela a seguir apresenta a taxa de urbanização da sociedade brasileira, em grande parte decorrente do processo de industrialização desenvolvido no país ao longo do século XX: 


\begin{tabular}{|c|c|}
\hline \multicolumn{2}{|c|}{ Brasil } \\
\hline Período & Taxa de urbanização \\
\hline 1940 & 31,24 \\
\hline 1950 & 36,16 \\
\hline 1960 & 44,67 \\
\hline 1970 & 55,92 \\
\hline 1980 & 67,59 \\
\hline 1991 & 75,59 \\
\hline 2000 & 81,23 \\
\hline
\end{tabular}

Fonte: (IBGE - Censo demográfico 1940-2010). ${ }^{13}$

As proposições para o ensino de língua portuguesa que se constituem e se distribuem mais amplamente a partir dos anos finais da década de 1970, período em que houve a inversão no perfil da sociedade brasileira, de mais rural para mais urbana, se caracterizam pela consideração de contínuos entre as variedades linguísticas que compõem o português no Brasil.

Como apontado anteriormente, a língua portuguesa é assim concebida unitariamente, guardando em seu interior as diferenças sociolinguísticas geracionais, regionais, estilísticas ou históricas. As diferenças teriam sido constituídas em função de diferenças culturais, resultantes de condições sociais, políticas e econômicas, entre os grupos sociais constituintes da sociedade brasileira. $\mathrm{O}$ trabalho pedagógico deveria se fazer de modo a evitar o conflito entre os valores sociais atribuídos a uma e outra variedades linguísticas, com o objetivo de não estigmatizar a variedade linguística do aluno, e, assim, sem confrontá-lo, levá-lo a se apropriar gradativamente da norma culta e da escrita padrão.

Mas parece ter sido um certo modo de apropriação da noção de letramento, em proposições acadêmicas e oficiais para o ensino de língua portuguesa, o que fortaleceu a ideia de um continum entre práticas orais e letradas, e, em decorrência, entre variedades linguísticas diversas.

A ideia de continuidade nas concepções sobre variação linguística, e a função que a noção de letramento vem nelas desempenhar, podem ser observadas na proposta de Bortoni-Ricardo (2004a; 2004b), que integra elementos relacionados à noção de letramento para a apreensão da situação sociolinguística no país. A proposta da autora é a de se adotar um modelo analítico que prevê a existência de três continua: rural-urbano, oralidade-letramento e de monitoração estilística. Tratase de associar a critérios de caráter estrutural ("dicotomia rural-urbano; 
região geográfica; rede de relações sociais; etc."), e a fatores funcionais ("grau de formalidade"; registros; etc."), um elemento de caráter cultural, o letramento, que integra no modelo os efeitos produzidos pela distribuição da escrita nas práticas sociais. Com o emprego analítico dos três eixos em relação, seria possível localizar mais precisamente a posição que determinado falante, com a variedade por ele usada, ocuparia na complexidade do contexto social.

Porém, fazendo retornar sobre esse modelo as discussões em torno da polarização de dois tipos de língua portuguesa (PB e PPB), e considerando-se a clivagem que se estabelece em sua distribuição, decorrente dos modos de exploração econômica historicamente implantados no país (com as desigualdade sociais que produz), pode-se apontar questões para a perspectiva de um continuum a ser percorrido pelos sujeitos em razão da apropriação gradual de elementos advindos de um de seus eixos. Neste caso, trata-se de considerar um dado em específico que é a não apropriação do sistema de escrita alfabética, o que impossibilita a plena participação em práticas de letramento, e, também, a monitoração estilística relacionada à expressão na modalidade escrita.

Um primeiro questionamento que se pode apresentar referese à desigualdade na distribuição da escrita mesmo em contextos onde o continuum rural-urbano apresenta menor relevância em função de o processo migratório ter já se saturado. Observado que, por dados do censo de 2010 do IBGE, 96,5\% da população brasileira habitam em meios urbanos, provavelmente a dicotomia rural-urbano já se tenha deslocado para a configuração de variedades urbanas concorrentes. Essas afirmações, no entanto, podem se mostrar relativizadas se se consideram os critérios utilizados para o recenseamento da população. ${ }^{14}$ Porém, mesmo se se avaliar a prevalência do rural na sociedade brasileira, pode-se questionar que haja de fato um continuиm, no que se refere à relação rural/urbano. Talvez uma hipótese mais forte seja a que prevê a existência de uma polarização linguística, uma vez que o PB estaria mais fortemente vinculado a uma certa parcela da população, com altos níveis de escolarização, em contexto urbano letrado, e em posições socioeconômicas mais valorizadas, e o PPB, às comunidades mais pobres, mais distantes da norma urbana culta $\mathrm{e}$ das práticas de letramento legitimadas.

Em ambos os casos (na relação rural/urbano; ou considerada a primazia de um ou de outro perfil demográfico), os dados sobre distribuição da escrita apontam que fatores relacionados ao econômico são determinantes do aprendizado ou não da escrita do português padrão. $\mathrm{O}$ analfabetismo se mostra relacionado à posição que ocupam na distribuição econômica os sujeitos da aprendizagem. 
Trata-se de diferenças entre classes sociais - as quais, como visto, no caso da América Latina, se constituíram a partir do escalonamento racial estabelecido no processo de colonização (QUIJANO, 2005) -, que não se colocam como um continuum, mas como oposições, obstáculos, interdições, explorações e resistências, etc.

No que se refere ao continum de monitoramento estilístico, talvez se possa considerar também sua possibilidade de ocorrência em contextos próprios a cada um dos polos que configuram a distribuição do português no Brasil (PB e PPB). Nesse caso, é preciso considerar que as possibilidades de atenção e de planejamento podem se fazer no interior de contextos específicos, sem que um princípio de continuidade se estabeleça entre os contextos em jogo. A participação em eventos de uso da escrita de forma esporádica e não continuada, como prevalece para muitos grupos sociais fundados em práticas de oralidade distantes da norma considerada culta, pode representar rupturas importantes no que se refere a possibilidades de monitoração estilística.

A continuidade referente ao monitoramento estilístico parece ser uma percepção muito produtiva para considerar as competências que um indivíduo desenvolve ao longo de sua existência em relação aos contextos de que efetivamente participa. Teríamos, em relação ao sujeito, um continuum de mais ou menos exercício de monitoramento estilístico, em função das necessidades colocadas a ele em dados contextos, e a possibilidade de usar, num evento, competências desenvolvidas em eventos anteriores. Porém, de um ponto de vista social, o que prevaleceria seria a descontinuidade, a diferença, os obstáculos de passagem de um contexto a outro. São possíveis monitoramentos estilísticos mais ou menos produtivos em contextos de prevalência do uso do PPB, por exemplo; mas essas competências não se aplicam produtivamente quando levadas a funcionar em contextos próprios ao $\mathrm{PB}$, pois nesse caso o monitoramento estilístico se desenvolve, principalmente, com a aprendizagem formal referenciada em eventos de letramento fundados na escrita padrão.

Apontamentos semelhantes se podem fazer em relação ao continum oralidade-letramento, uma vez que usos sociais de linguagem se fazem com características específicas em contextos diversos, sem que, necessariamente, haja solução de continuidade entre eles. Novamente, é possível pensar num sujeito que, em seu percurso formativo, percorra contextos e participe de práticas de letramento próprias a lugares sociais desprivilegiados, e de práticas de letramento valorizadas pelas classes privilegiadas. Tal continuum talvez possa ser observado do ponto de vista social em sociedades que tenham uma estruturação socioeconômica mais horizontalizada, como a que se 
observa nas discussões de Bourdieu (2007), por exemplo, para a sociedade francesa de meados do século XX. A ascensão social, nos casos por ele discutidos, é tratada em razão de um escalonamento social em que se marcam diferenças, mas, ainda assim, considerada uma mobilidade possível em função da apropriação de bens simbólicos e da tentativa de apreensão do valor relativo desses bens simbólicos em referência aos grupos que os detêm.

É algo diverso quando se considera a distribuição dos bens simbólicos em sociedades caracterizadas pela desigualdade extrema, dentre eles, aqueles que compõem práticas de oralidade e de letramento. No caso brasileiro, a apropriação e manutenção dos bens próprios à cultura letrada são fortemente controladas por processos mercantis, mantidos circunscritos à parcela da população que possui os recursos financeiros suficientes para realizar investimentos nesse mercado, na compra de serviços e produtos educacionais.

A divisão, na sociedade brasileira, entre tipos de escolarização aquela para os que possuem recursos econômicos, e aquela para os que não os possuem - representa a divisão, a clivagem, entre culturas orais e culturas letradas específicas, que podem ser associadas à polarização em que se fundamenta a distribuição dos dois tipos de português, no país. Políticas de afirmação e de garantia do acesso das populações pobres à educação formal têm sido a resposta de alguns governos, no país, para essa situação. Essas políticas, que confrontam o statu quo, no entanto, são fortemente combatidas pelas elites brasileiras, como pode ser visto nos ataques à democracia que se realizam historicamente no Brasil quando essas elites se sentem minimamente ameaçadas.

Nesse sentido, o que parece de fato operar entre as variedades linguísticas e sua distribuição não é a continuidade, mas as clivagens, as distâncias, as interdições, as rupturas.

\section{CONSIDERACְ̃̃ES FINAIS}

No Brasil, uma realidade linguística clivada responde às desigualdades econômicas ao definir uma fronteira, um limite, entre dois subsistemas que, associados que estão à distribuição escolar da norma culta e da escrita padrão, bem como à valoração social das práticas de oralidade e de letramento, garantem diferenças suficientes para que se restrinja ou impeça a mobilidade entre eles (principalmente a mobilidade no sentido $\mathrm{PPB}=>\mathrm{PB}$ ). Ao mesmo tempo, a representação social desse sistema linguístico como uma unidade projeta a imagem de que não existem (sub)sistemas 
linguísticos entre os diferentes tipos de português falados no Brasil, mas uma só língua, com diferenças estabelecidas num continuum.

Em resposta a essa imagem, propostas para o ensino da língua portuguesa produzidas nas últimas cinco décadas, no país, se fundamentam na ideia de que seja possível operar, na escola, a aproximação entre línguas ou variedades de língua: com o uso de instrumentos como a gramática e o dicionário, de acordo com os defensores do ensino tradicional; ou com atividades de produção de textos sustentadas em análise linguística, seriam superadas as distâncias entre a língua do aluno e a língua da escola no interior dos processos de ensino e de aprendizagem. Tanto num caso, como no outro, parte-se do princípio de que o ensino do português no país se realiza no interior de uma unidade linguística e consiste em substituir a variedade linguística do falante pelas variedades socialmente legitimadas, ou somar estas à(s) que já possui.

Desse modo, produziu-se um outro espaço de conflito entre a língua da escola e a do falante do PPB: ao pressupor que o falante já possui a gramática do português (seja do português europeu, seja do português brasileiro) como gramática de sua língua materna, afirmase ao aprendiz que ele não é capaz de utilizar um conhecimento que ele supostamente já tem, o que se confirma quando as avaliações escolares the informam que ele não é capaz de reproduzir o padrão da escrita ou a norma falada culta quando lhe é solicitado que o faça. Trata-se, nesse caso, não do apontamento de falta de conhecimento, mas de incapacidade. Posiciona-se o sujeito no lugar de um aparente paradoxo: ele é competente (pois supostamente tem a estrutura gramatical de sua língua), e é incompetente (pois é incapaz de utilizar essa competência e aperfeiçoá-la). O paradoxo é apenas aparente porque se fundamenta na caracterização de uma falta que é atribuída ao indivíduo, quando, de fato, é fundada socialmente.

É preciso, portanto, que as diferenças linguísticas no país não sejam ocultadas, denegadas, em favor de uma representação de unidade linguística que é tão discriminatória quanto a crença na existência da igualdade racial no país: num caso e no outro, e justamente porque são fatores historicamente inter-relacionados, negar a diferença é contribuir para a permanência da desigualdade.

Atualizar as propostas de renovação do ensino de língua portuguesa, nesse sentido, parece ser possível com a consideração das características que a sociedade brasileira passou a ter após as mudanças sociais e econômicas que se realizaram nas últimas décadas do século XX e iniciais do século XXI. Os preceitos neoliberais e a perda da autonomia que o processo de globalização determinou para 
os Estados-nação (SANTOS, 2000) deslocaram a função social das línguas nacionais. Uma escola libertadora precisa responder aos desafios apresentados por essas novas condições em que o valor social da língua se estabelece em função do valor econômico investido para a produção e aquisição de produtos com maior valor agregado no mercado linguístico. É preciso, portanto, observar as diferenças linguísticas não apenas como fator de manutenção e legitimação das posições sociais, mas como fator de produção das desigualdades econômicas.

\section{REFERÊNCIAS}

AFONSO, A. J. Estado, mercado, comunidade e avaliação: Esboço para uma rearticulação crítica. Educação \& Sociedade, ano XX, nº 69, Dez., 1999.

AMARAL, N. F. G. Clichês em redações de vestibular: estratégia discursiva. Dissertação de Mestrado. Orientador: Sírio Possenti. IEL/UNICAMP, 1996.

APARÍCIO, A. S. M. A renovação do ensino de gramática no primeiro grau no Estado de São Paulo. Dissertação (Mestrado em Linguística Aplicada). Universidade Estadual de Campinas. Instituto de Estudos da Linguagem, Campinas, SP, 1999.

AUROUX, S. A revolução tecnológica da gramatização. Campinas, SP: Editora da UNICAMP, 2000.

BAGNO, M. Português no Brasil: herança colonial e diglossia. Revista da FAEEBA, Salvador, no 15, p. 37-47, jan./jun., 2001.

BASTOS, L. K. X. Coesão e coerência em narrativas escolares escritas. Dissertação de Mestrado. Campinas: FE/UNICAMP, 1984.

BEISIEGEL, C. de R. Os primeiros tempos da pesquisa em sociologia da educação na USP. Educação e Pesquisa. [online], vol.39, n.3, p. 589-607, 2013.

BORTONI-RICARDO, S. M.. Educação em língua materna: a sociolinguística na sala de aula. São Paulo: Parábola Editorial, 2004a

BORTONI-RICARDO, S. M. Um modelo para a análise sociolinguística do português do Brasil. In: BAGNO, M. (org.). Linguística da Norma. São Paulo: Edições Loyola, $2004 b$.

BORTONI-RICARDO, S. M. O Presidente Lula e os contínuos de urbanização, letramento e monitoração estilística. Revisitando os contínuos de urbanização, letramento e monitoração estilística na análise do português do Brasil. In DIETRICH, W. e NOLL V. (org.). O Português do Brasil - perspectivas da pesquisa atual. Frankfurt: Vervuert/ Iberamericana, p. 195-201, 2004c.

BOURDIEU, P. A economia das trocas linguísticas. Trad. Paulo Montero. In: ORTIZ, R. (org.). Pierre Bourdieu. São Paulo: Ática, 1994. (Original: Langue Française, 34, maio 1977).

BOURDIEU, P. A economia das trocas simbólicas. São Paulo: Perspectiva, 2007.

BRASIL. Secretaria de Educação Fundamental. Parâmetros curriculares nacionais: língua portuguesa. Secretaria de Educação Fundamental. Brasília: MEC/SEF, 1997. 
BRASIL. Secretaria de Educação Fundamental. Parâmetros curriculares nacionais: terceiro e quarto ciclos do ensino fundamental: língua portuguesa. Secretaria de Educação Fundamental. Brasília: MEC/SEF, 1998.

BRONCKART, J.-P. Le fonctionnement des discours: un modèle psychologique et une méthode d'analyse. Neuchatel-Paris: Delachaux \& Niestlé, 1985.

CASTILHO, A. T. Os sons. In: SÃO PAULO. Secretaria da Educação. Subsídios à Proposta Curricular de Língua Portuguesa para o $1^{\circ}$ e $2^{\circ}$ graus - coletânea de textos. São Paulo: CENP, vol. 1, 1988a.

CASTILHO, A. T. Variação linguística, norma culta e ensino da língua materna. In: SÃO PAULO. Secretaria da Educação. Subsídios à Proposta Curricular de Língua Portuguesa para o $1^{\circ}$ e $2^{\circ}$ graus - coletânea de textos. São Paulo: CENP, vol. 1, 1988b.

CHAUÍ, M. Uma nova classe trabalhadora. In: SADER, E. (org.) 10 anos de governos pósneoliberais no Brasil: Lula e Dilma. São Paulo, SP: Boitempo; Rio de Janeiro: FLACSO Brasil, 2013.

DUARTE, J. M. Produção escrita de alunos da escola pública: a possível contribuição da semiótica. Tese (Doutorado em Semiótica e Linguística Geral). Orientador: Irenilde Pereira dos Santos. FFLCH/USP, 1992.

FELTRAN, G. de S. O valor dos pobres: a aposta no dinheiro como mediação para o conflito social contemporâneo. Cadernos CRH [online]. vol.27, n.72, p. 495-512, 2014.

FERRARO, A. R. Analfabetismo e níveis de letramento no Brasil: o que dizem os censos? Educação e Sociedade. Campinas, v. 23, n. 81, p.21-47, dez., 2002. Disponível em: < http:/ / www.cedes.unicamp.br>. Acesso em: 25 abr. 2007.

FERRARO, A. R.; KREIDLOW, D. Analfabetismo no Brasil: configuração e gênese das desigualdades regionais. Educação e Realidade, Porto Alegre, v. 29, n. 2, p. 179-200, jul./ dez., 2004.

FREITAS, L. C. A avaliação e as reformas dos anos de 1990: novas formas de exclusão, velhas formas de subordinação. Educação \& Sociedade [online]. vol.25, n.86, p. 131-170, 2004.

FREITAS, M. C. de. Desempenho e adaptação da criança pobre à escola: o padrão de pesquisa do CRPE-SP. Educação e Pesquisa. [online]. vol.40, n.3, p. 683-698, 2014.

GERALDI, J. W.; SILVA, L. L. M. \& FIAD, R.S. Linguística, Ensino de Língua Materna e Formação de Professores. In D.E.L.T.A., vol.12, n 2, p. 307-326, 1996.

GERALDI, C. M. G.; GERALDI, J. W. A domesticação dos agentes educativos: há alguma luz no fim do túnel. Revista Inter-Ação, vol. 37, nº 1, p. 37-50, 2012.

GUEDES, M. Q. Parâmetros Curriculares Nacionais ou o currículo oficial? Revista InterAção, vol. 27, nº 2, p. 85-99, 2002.

HADDAD, S.; SIQUEIRA, F. Analfabetismo entre jovens e adultos no Brasil. Revista Brasileira de Alfabetização, v. 1, n. 2, p. 88-110, jul./dez., 2015.

INSTITUTO BRASILEIRO DE GEOGRAFIA E ESTATÍSTICA (IBGE). Atlas do Censo Demográfico 2010. Rio de Janeiro: IBGE, 2013.

KATO, M.A. O ensino de línguas após a implantação da linguística. In: Boletim da Abralin: 51-59, 1983. 
LOBATO, L. M. P. Sobre a questão da influência ameríndia na formação do Português do Brasil. Revista de Estudos Linguísticos, Belo Horizonte, v. 14, n. 2, p. 11-47, jun./dez., 2006.

LOPES, F. Para além das barreiras dos números. Desigualdades raciais e saúde. Caderno de Saúde Pública, Rio de Janeiro, vol. 21, n. 5, p. 1595-1601, set./out., 2005.

LUCCHESI, D. As duas grandes vertentes da história sociolinguística do Brasil. D.E.L.T.A., São Paulo, v. 17, n. 1, p. 97-130, 2001.

LUCCHESI, D. O conceito de transmissão linguística irregular e o processo de formação do português no Brasil. In: RONCARATI, C.; ABRAÇADO, J. (org.) Português brasileiro: contato linguístico, heterogeneidade e história. Rio de Janeiro: 7 letras, 2003.

LUCCHESI, D. Parâmetros sociolinguísticos do português brasileiro. Revista da ABRALIN, v. 5, n. 1/2, p. 83-112, dez. 2006.

LUCCHESI, D. Africanos, crioulos e a língua portuguesa. In: LIMA, I. S.; CARMO, L. do (org.). História social da língua nacional. Rio de Janeiro: Casa de Rui Barbosa, p.151-180, 2008.

LUCCHESI, D. A diferenciação da língua portuguesa no Brasil e o contato entre línguas. Estudos de Linguística Galega, n. 4, p. 45-65, 2012.

LUCCHESI, D. Língua e sociedade partidas: a polarização sociolinguística no. Brasil. São Paulo: Contexto, 2015.

MARINHO, M. A oficialização de novas concepções para o ensino de Português. TESE (Doutorado) Universidade Estadual de Campinas. Instituto de Estudos da Linguagem. Campinas, 2001.

MATTOS E SILVA, R. V. Da sócio-história do português brasileiro para o ensino do português no Brasil hoje. Revista da FAEEBA, Salvador, nº 15, p. 23-35, jan./jun., 2001.

MIGNOLO, W. D. Desobediência epistêmica: a opção descolonial e o significado de identidade em política. Cadernos de Letras da UFF: Dossiê: Literatura, língua e identidade, n.34, p. 287-324, 2008.

MOREIRA, T. M. A progressão temática na redação escolar. Dissertação de Mestrado. Orientador: Angela Kleiman. IEL/UNICAMP, 1991.

NARO, A.; SCHERRE, M. Sobre as origens do português popular do Brasil. DELTA 9, p. 437-454, 1993.

NARO, A.; SCHERRE, M. Origens do português brasileiro. São Paulo: Parábola, 2007.

OLIVEIRA, R. P. A transformação da educação em mercadoria no Brasil. Educação e Sociedade, Campinas, v. 30, n. 108, p. 739-760, out., 2009.

PAGOTTO, E. G. Norma e condescendência: ciência e pureza. In: Línguas e Instrumentos Linguísticos, São Paulo, v.2, p.49-68, 1999.

PAGOTTO, E. Crioulo sim, crioulo não: uma agenda de problemas. In: CASTILHO, A.; TORRES MORAIS, M. A.; CYRINO, S. M. L.; LOPES, R. (org.) Português Brasileiro: descrição, história e aquisição. Campinas: Pontes, p. 461-482, 2007.

PERONI, V. M. V.; CAETANO, M. R. O público e o privado na educação Projetos em disputa?, Revista Retratos da Escola. Brasília, v. 9, n. 17, p. 337-352, jul./dez. 2015. Disponível em http://esforce.org.br. Acesso em: 27 abri. 2018. 
PESIRANI, M. M. A. A constituição do discurso construtivista em documentos oficiais de referência curricular para a alfabetização produzidos nas décadas de 1980 e 1990. Dissertação (Mestrado em Educação). Universidade de São Paulo. Faculdade de Educação. São Paulo, 2014.

PETRONI, M. R. A organização do texto escrito por alunos do $1^{\circ}$ grau. Dissertação de Mestrado. Orientador: Maria Cecília Perroni. IEL/UNICAMP, 1994.

PETTER, M. M. T. Línguas africanas no Brasil. Gragoatá, Niterói, n. 19, p. 193-217, $2^{\circ}$ sem., 2005.

PIETRI, E. de. A constituição do discurso da mudança no ensino de língua materna no Brasil. 2003. Tese (Doutorado em Linguística Aplicada) - Universidade Estadual de Campinas. Instituto de Estudos da Linguagem. Campinas, 2003.

PIETRI, E. de. A constituição da escrita escolar em objeto de análise dos estudos linguísticos. Trabalhos em Linguística Aplicada, v.46, n. 2, p. 283-297, jul./dez. 2007.

PIETRI, E. de. Sobre a constituição da disciplina curricular de língua portuguesa. Revista Brasileira de Educação, Rio de Janeiro, v.15, n. 43, p.70-83, Apr. 2010.

QUIJANO, Aníbal. Dom Quixote e os moinhos de vento na América Latina. Estudos Avançados, São Paulo, v. 19, n. 55, p. 9-31, Dec., 2005.

RIBEIRO, V. M.; VÓVIO, C. L.; MOURA, Mayra P. Letramento no Brasil: alguns resultados do indicador nacional de alfabetismo funcional. Educação e Sociedade, vol. 23, n. 81, p. 49-70, 2002.

ROCCO, M. T F. Texto e Discurso: uma caracterização da linguagem escrita de candidatos a vestibulares. Tese de Doutorado. São Paulo: FEUSP, 1981.

SADER, E. A construção da hegemonia pós-neoliberal. In: SADER, E. (org.) 10 anos de governos pós-neoliberais no Brasil: Lula e Dilma. São Paulo, SP: Boitempo; Rio de Janeiro: FLACSO Brasil, 2013.

SANTOS, M. Por uma outra globalização (Do pensamento único à consciência universal). São Paulo: Record, 2000.

SOARES, M. Linguagem e escola: uma perspectiva social. São Paulo: Ática, 1986.

\section{NOTAS}

${ }^{1}$ TARALLO, Fernando. Sobre a alegada origem crioula do português brasileiro: mudanças sintáticas aleatórias. In: ROBERTS, Ian; KATO, Mary (org.) Português Brasileiro - Uma viagem diacrônica. Campinas: Ed. UNICAMP, p. 35-68, 1993.

${ }^{2}$ Sobre as reformas de caráter neoliberal na Educação brasileira, ver FREITAS (2004).

${ }^{3}$ Cf.: LUCCHESI (2003, 2006, 2012), e discussão realizada na sequência.

${ }^{4}$ No exemplo apresentado por Lobato (2006), abaixo reproduzido, a leitura feita do argumento, no $\mathrm{PB}$, seria extensional — parte do argumento interno do verbo ("o pneu do meu carro") pode ser levada à posição de sujeito, enquanto parte se posiciona como objeto (sentença 1): 
(1) O meu carro furou o pneu. (PE: *, PB: OK)

(2) a. Furou o pneu do meu carro. (PE: OK, PB: OK)

b. O pneu do meu carro furou. (PE: OK, PB: OK)

A ocorrência 1 seria agramatical no PE devido a, neste, o preenchimento do argumento do verbo se fazer a partir da identificação do argumento em seu todo: a interpretação temática se faz com base em leitura intensional, o que impede que a estrutura interna do argumento seja analisada.

${ }^{5} \mathrm{O}$ termo refere-se a espaço (por vezes, de transição) constituído entre o rural e o urbano.

${ }^{6}$ As rupturas nos processos de aquisição da escrita podem ser evidenciadas pelo número importante de trabalhos acadêmicos sobre escrita escolar (cf.:, dentre outros, ROCCO (1981); BASTOS (1984); MOREIRA (1991); DUARTE (1992); PETRONI (1994); AMARAL (1996), que apontam, historicamente, para os problemas de aquisição da escrita nos processos de escolarização, parte significativa desses estudos observando produções escritas de alunos no final do ensino básico. A própria constituição da escrita escolar em objeto dos estudos linguísticos, no Brasil, na década de 1970, responde a essa problemática (cf.: PIETRI, 2007). O problema da aquisição da escrita é observado também em artigos sobre a distribuição da alfabetização no país (cf.: LOPES, 1995; FERRARO, 2002; RIBEIRO, VÓVIO \& MOURA, 2002; FERRARO \& KREIDOW, 2004; HADDAD \& SIQUEIRA, 2015).

${ }^{7}$ Mesmo em estudos que preveem um certo tipo de polarização linguística, a ideia de continuum prevalece, como em BAGNO (2001), ou em MATTOS E SILVA (2001): na primeira referência, o autor considera um caso de diglossia as diferenças linguísticas existentes no português do Brasil. Já Mattos e Silva observam a polarização em relação às diferenças entre o português padrão ensinado na escola tradicional e o português de fato falado no país. Num caso e no outro, concebe-se uma unidade linguística. No presente trabalho, como mencionado, a polarização é observada em bases históricas, em que se constituíram um português brasileiro, com sua norma socialmente valorizada como culta e associada a práticas de letramento legitimadas; e um português popular brasileiro, resultante do aprendizado do português como língua estrangeira por falantes adultos em situação de exploração econômica (LOBATO, 2006; LUCCHESI, 2003; e, num sentido um pouco diverso, PAGOTTO, 2007).

${ }^{8}$ Lucchesi (2015) argumenta em favor do processo histórico de clivagem do português distribuído no Brasil, propondo, entretanto, que a oferta de escolarização e a constituição de sujeitos em contextos letrados produziria um processo de graduação numa realidade sociolinguística antes fortemente polarizada. Nesse sentido, o autor propõe uma estimativa da distribuição sociolinguística no país em função do contingente populacional que completaria determinados ciclos escolares. Com isso, teríamos em referência ao ano 2000, a seguinte distribuição: falantes da norma culta (sujeitos com curso de nível superior completo): 6,77\% da população; falantes de norma semiculta (sujeitos com curso de ensino médio completo): $16,35 \%$ da população; falantes de norma semiculta (sujeitos com curso de ensino médio completo): $16,35 \%$ da população; falantes de norma média (sujeitos com curso de ensino fundamental completo): $12,85 \%$ da população; falantes de norma média baixa (sujeitos com curso de ensino fundamental incompleto): $30,62 \%$ da população; falantes de norma popular (sujeitos com pouca ou nenhuma experiência de escolarização): 33,4\% da população. Note-se, nesta distribuição, que a proporção de falantes que se apropriam da norma culta ou semiculta é de em torno de um terço da população total: esse percentual de $30 \%$ de falantes que efetivamente podem se apropriar dos usos do português brasileiro parece se manter constante desde o período do Brasil-Colônia (trata-se da proporção que 
impediu o desenvolvimento dos processos de crioulização), o que também evidencia a reprodução da desigualdade socioeconômica como um elemento constituinte da formação do Brasil em seu processo histórico.

${ }^{9}$ Essa função do Estado vale também para as elites, mas no plano das relações internacionais: o Estado é historicamente utilizado para garantir a submissão dos interesses nacionais aos interesses dos dominadores externos (os norte-americanos e os países centrais da Europa ocidental).

${ }^{10}$ BONVINI, E.; PETTER, M.M.T. Portugais du Brésil et langues africaines. Paris: Larousse. 1998. (Langages, p. 130).

${ }^{11}$ A referência a América pode incluir a América do Norte, ainda que os Estados Unidos, em razão do modelo de colonização inglês, e dos desdobramentos pela descolonização norteamericana, venha a poder ocupar, mais adiante, o lugar de potência militar e econômica em face de outros países e regiões. No entanto, o regime de hierarquização racial apontado por Quijano (2005) vale também para os Estados Unidos da América, como se depreende pela observação, até a atualidade, dos conflitos naquele país.

${ }^{12}$ Cf.: LOBATO (2006).

${ }^{13}$ IBGE - Séries Históricas e Estatísticas. http:// seriesestatisticas.ibge.gov.br/series.aspx?no $=10 \&$ op $=2 \&$ vcodigo $=$ POP122\&t $=$ taxa-urbanizacao. Acesso em: 15 mai. 2017.

${ }^{14}$ Segundo Bortoni-Ricardo (2004c), "Eli da Veiga argumenta que os parâmetros da OCDE (Organização de Cooperação e Desenvolvimento Econômico) são mais adequados que a metodologia oficial do IBGE. Segundo a OCDE, para um município ser considerado urbano, teria de apresentar uma densidade demográfica de 150 habitantes $/ \mathrm{km}^{2}$ e uma população nunca menor que 50 mil habitantes. Se aplicados esses parâmetros, os 5.507 municípios brasileiros considerados urbanos passariam a 411".

Submetido: 01/06/2017

Aprovado: 06/04/2018

Contato:

Emerson de Pietri

Universidade de São Paulo - Faculdade de Educação

Avenida da Universidade, 308, Cidade Universitária

São Paulo $\mid$ SP|Brasil

CEP 05.508-040

E-mail:<pietri@usp.br> 